\title{
A TUTELA DAS CRIAÇÕES \\ INTELECTUAIS E A EXISTÊNCIA DO DIREITO DE AUTOR NA ANTIGUIDADE CLÁSSICA
}

\section{Leonardo Estevam de Assis Zanini}

\section{RESUMO}

O artigo aborda a proteção das criações intelectuais nas civilizações da Antiguidade Clássica. Inicia fazendo um breve estudo do tema na Grécia Antiga, passando, em seguida, ao estudo do Direito Romano. Analisa a consciência dos romanos em relação à proteção dos interesses morais do autor, o interesse econômico na produção intelectual e a possibilidade de tutela dos direitos da personalidade do autor pela actio iniuriarum. Por fim, aborda a discussão relativa à existência do Direito de Autor na Antiguidade Clássica.

Palavras-chave: Direito de Autor. Direitos da personalidade. Direitos intelectuais. Direitos morais do autor. Direito romano. Actio iniuriarum. Direito grego. Direito de paternidade. Direito de divulgação. Direito à integridade. 


\section{INTRODUÇÃO}

A tutela das criações intelectuais, na história do Direito, não foi simplesmente ignorada, passando a ser objeto de regulamentação apenas a partir dos decretos revolucionárias franceses de 1791 e 1793.

De fato, ainda que de forma incipiente, se comparamos com nossa realidade, há inúmeros registros históricos da proteção do autor em épocas bastante remotas, como é o caso das civilizações grega e romana.

Nesse contexto, para uma melhor compreensão da necessidade de proteção das criações intelectuais na atualidade, focaremos, no presente trabalho, a eventual tutela concedida às obras do espírito na Antiguidade e procuraremos responder à indagação acerca da existência do Direito de Autor nas civilizações grega e romana.

\section{A PROTEÇÃO AUTORAL NA GRÉCIA ANTIGA}

$\mathrm{Na}$ Grécia antiga, após o surgimento da escrita, era comum a transcrição de obras de vários escritores, as quais, a cada nova cópia, sofriam transformações, manipulações e modificações. Tal atividade era considerada lícita, visto que para os antigos gregos a imortalidade correspondia à recordação, ao fato de que após a morte do autor as novas gerações continuariam a aprender com seu trabalho, não importando se a obra tinha sido alterada ${ }^{152}$.

A cultura da época era predominantemente oral, de maneira que a literatura era bastante limitada e tinha que ser avaliada de acordo com as condições existentes. Era então compreensível, até pela necessidade de desenvolvimento das letras, a ausência de punição de determinadas condutas, hoje vedadas pelo Direito de Autor.

Assim, fica evidente que após a distribuição da "primeira cópia de um livro, o autor não mais podia controlar seu destino", pois não havia nenhuma forma de proteger a integridade de um texto ou de limitar o seu número de cópias ${ }^{153}$.

\footnotetext{
152 GAUDENZI, Andrea Sirotti. Il nuovo diritto d'autore. Santarcangelo di Romagna: Maggioli, 2009. p. 41.

153 CARBONI, Guilherme. Direito Autoral e autoria colaborativa: na economia da informação em rede. São Paulo: Quartier Latin, 2010. p. 34.
} 
Em Atenas, entretanto, uma lei do ano de 330 a.C. mostrou-se bastante avançada, ordenando o depósito de cópias exatas das obras dos três grandes clássicos nos arquivos estatais. Com isso, os atores e copistas deveriam respeitar o texto depositado, já que, até então, havia pouca consideração pelo texto original ${ }^{154}$.

Também no mundo helênico, por volta de 650 a.C., sabe-se que muitos pintores de vasos, como Aristonotos, Exekias, Eutimedes, Euphiletos e outros, garantiam o reconhecimento da autoria com a aposição de sua assinatura na obra ${ }^{155}$, preservando-se, desse modo, o direito de paternidade.

Procedimento semelhante foi adotado pelo renomado poeta Teógnis de Mégara, que criou um sinal identificativo de suas obras, com o objetivo de evitar a sua utilização sem indicação da autoria, bem como para garantir a integridade do texto ${ }^{156}$.

Outra manifestação interessante diz respeito às acusações de plágio. Era bastante comum a promoção de concursos em que o vencedor era aclamado publicamente e recebia prêmios. Em vista disso, sabe-se que acusações por plágio eram frequentes, lembrando Daniel Rocha que:

Philóstrato de Alexandria acusava Sófocles de ter aproveitado de Ésquilo. A Ésquilo, de ter feito o mesmo com Frínico. A Frínico, de agir assim com seus antecessores.

Platão censurava Eurípedes pela reprodução literal em seus coros da filosofia de Anaxágoras. Aristófanes, em "As rãs”, não poupa Eurípedes, e propõe que se coloque num prato da balança apenas os seus versos, e no outro, Eurípedes, mulher e filhos e Cephisophon (amigo e colaborador de Eurípedes) com todos os livros.

Aristófanes não ficou imune à acusação de haver se aproveitado de Crátinos e Eupólis, o que levou a

${ }^{154}$ LIPSZYC, Delia. Derecho de autor y derechos conexos. Buenos Aires: UNESCO, 1993. p. 28.

155 FRAGOSO, João Henrique da Rocha. Direito autoral: Da Antiguidade à Internet. São Paulo: Quartier Latin, 2009. p. 58.

${ }^{156}$ Idem. p. 56-57. 
qualificar este último de "miserável plagiário" de sua obra Les Chevaliers (“As nuvens" - verso 553) 157.

É igualmente digno de nota, conforme relatou Suidas, o fato de que "Euforion, filho de Ésquilo, teria conquistado por quatro vezes a vitória nos torneios de tragédia, apresentando peças inéditas de seu pai como suas". Isso levou Daniel Rocha a afirmar que o filho também herdava a obra intelectual paterna inédita como se fora uma res comum ${ }^{158}$.

Por outro lado, não se pode negar o interesse da pólis na coibição do plágio, o que guardava relação com a correta atribuição de autoria dos livros depositados nas bibliotecas gregas ${ }^{159}$.

Vê-se, portanto, que os gregos já tinham uma consciência incipiente acerca da necessidade da proteção da integridade e da paternidade da obra. No entanto, isso não nos permite afirmar que se fazia presente naquela sociedade o Direito de Autor.

\section{A SITUAÇÃO DO AUTOR NO DIREITO ROMANO}

Os romanos não eram dotados de muita imaginação artística, por isso suas artes derivavam basicamente de influências recebidas de povos conquistados, especialmente dos gregos. Entrementes, é certo que os romanos deixaram sua marca nas artes herdadas ${ }^{160} \mathrm{e}$, ao que tudo indica, também deram sua contribuição, ainda que embrionária, ao que viria a ser conhecido como Direito de Autor.

A ausência de disposição legal específica acerca das criações intelectuais não significou que os escritores e artistas em geral não pudessem ser, de alguma forma, pelo menos em tese, amparados pelo Direito Romano ${ }^{161}$.

\footnotetext{
${ }^{157}$ ROCHA, Daniel. Direito de autor. São Paulo: Irmãos Vitale, 2001. p. 14.

${ }^{158}$ ROCHA, Daniel. Direito de autor. São Paulo: Irmãos Vitale, 2001. p. 14.

159 CARBONI, Guilherme. Direito Autoral e autoria colaborativa: na economia da informação em rede. São Paulo: Quartier Latin, 2010. p. 34.

${ }^{160}$ EBOLI, João Carlos de Camargo. Pequeno mosaico do direito autoral. São Paulo: Irmãos Vitale, 2006. p. 17.

${ }^{161}$ COSTA NETTO, José Carlos. Direito autoral no Brasil. 2. ed. São Paulo: FTD, 2008. p. 52.
} 
Ao contrário, pode-se notar que os romanos tinham consciência acerca do direito moral e patrimonial de autor. Apesar disso, não são conhecidas regras específicas a esse respeito e também não são conhecidos casos em que autores contestaram judicialmente o desrespeito à autoria ${ }^{162}$.

\section{A CONSCIÊNCIA DOS ROMANOS EM RELAÇÃO AOS INTERESSES ESPIRITUAIS E MORAIS DO AUTOR}

Os romanos realmente estavam cientes do fato de que a publicação e a exploração da obra guardava íntima ligação com interesses espirituais e morais, tanto é que cabia ao autor a decisão quanto à divulgação ou não de seu trabalho e os plagiadores eram mal vistos pela sociedade ${ }^{163}$.

Aliás, em Roma, tal qual na Grécia, era corrente o problema do plágio, palavra que chegou ao português pelo latim (plagium), decorrendo das previsões da Lex Fabia de Plagiariis, do século segundo antes de Cristo. O plágio do direito romano, entretanto, não tinha nada a ver com a acepção atual da palavra ${ }^{164}$, pois os romanos, sob o nome de plagium, puniam "a escravização de homem livre, bem como a compra e venda ou assenhoreamento de escravo alheio" ${ }^{165}$.

Contudo, a expressão sofreu desvio histórico, atribuído ao poeta Marco Valério Marcial (42-104 d.C.), que comparou seus epigramas a escravos libertos, os quais estariam nas mãos de um sequestrador de nome Fidentino (plagiarius) ${ }^{166}$.

162 SCHICKERT, Katharina, Der schutz literarischer urheberschaft im rom der klassischen antike, p. 66. Rehbinder, igualmente, aponta a inexistência, na Antiguidade, do reconhecimento de um direito do autor a um bem espiritual, não obstante a perfeita consciência acerca de uma "propriedade espiritual" (REHBINDER, Manfred, Urheberrecht, p. 7).

${ }^{163}$ LIPSZYC, Delia. Derecho de autor y derechos conexos. Buenos Aires: UNESCO, 1993. p. 28.

164 Conforme esclarece Chinellato, durante a Renascença os "jurisconsultos Duareno e Tomásio concluíram que o plágio era punido pela Lex Fabia de Plagiariis, entendimento que foi seguido por autores modernos, o qual, no entanto, baseou-se em erro" (CHINELLATO, Silmara Juny de Abreu. Notas sobre plágio e autoplágio. Revista do Instituto dos Advogados de São Paulo, São Paulo, v. 29, p. 305-328, jan./jun. 2012, p. 306).

165 HUNGRIA, Nélson. Comentários ao Código Penal. 5 ed. Rio de Janeiro: Forense, 1982, v. 6. p. 198.

${ }^{166}$ REHBINDER, Manfred. Urheberrecht. 16. ed. München: C. H. Beck, 2010. p. 7. 
Marcial escreveu em seus epigramas (Epigrama 30, Livro I): "Segundo consta, Fidentino, tu lês os meus trabalhos ao povo como se fossem teus. Se queres que os digam meus, mandar-te-ei de graça os meus poemas; se quiseres que os digam teus, compra-os, para que deixem de ser meus". E no quinto Epigrama asseverou ainda o escritor latino: "Quem busca a fama por meio de poesias alheias, que lê como suas, deve comprar não o livro, mas o silêncio do autor" 167.

Outro caso célebre de plágio envolveu Virgílio e Batilo. O autor da Eneida, ainda desconhecido do público, acusou Batilo de se apropriar da paternidade de um texto em honra de Augusto ${ }^{168}$. Era época de jogos e Virgílio escreveu anonimamente, durante a noite, no pórtico do palácio imperial, em honra do imperador, o seguinte dístico:

Nocte pluit tota, redeunt spectacula mane

Divisum imperium cum Jove Caesar habet ${ }^{169}$.

O imperador, então, sentindo-se lisonjeado, quis saber quem tinha escrito os versos, apresentando-se Batilo como o autor. Inconformado, Virgílio, novamente de forma anônima, acrescentou aos versos anteriores mais um outro verso, seguido de quatro outros incompletos e repe$\operatorname{tidos}^{170}$ :

Hos ego versiculos fecit, tulit alter honoris:

Sic vos non vobis

Sic vos non vobis

Sic vos non vobis

Sic vos non vobis

${ }^{167}$ ROCHA, Daniel. Direito de autor. São Paulo: Irmãos Vitale, 2001. p. 15.

168 GAUDENZI, Andrea Sirotti. Il nuovo diritto d'autore. Santarcangelo di Romagna: Maggioli, 2009. p. 41.

169 "Chove a noite toda, de manhã recomeçam os jogos. Deste modo, César divide o poder com Júpiter”. Tradução de Mauro Mendes (MENDES, Mauro. Virgílio e os cantadores. Disponível em: <http://www.arquivors.com/mmendes_virgilio.pdf>. Acesso em: 9 jan. 2011).

170 MENDES, Mauro. Virgílio e os cantadores. Disponível em: <http://www.arquivors.com/mmendes_virgilio.pdf>. Acesso em: 9 jan. 2011. 
Diante do texto, o imperador Augusto pediu a Batilo a sua complementação, no entanto, o mesmo não obteve êxito na tarefa, dando espaço para Virgílio, seu verdadeiro autor, que completou os versos da seguinte forma ${ }^{171}$ :

Hos ego versiculos fecit, tulit alter honoris:

Sic vos non vobis nidificates aves,

Sic vos non vobis vellera fertis oves,

Sic vos non vobis mellificatis apes,

Sic vos non vobis fertis aratra boves ${ }^{172}$,

E para além de todos esses casos, é muito marcante um episódio envolvendo uma disputa entre Cícero e o editor Dorus, que foi analisada de forma bastante sóbria por Sêneca, não deixando dúvida acerca da consciência dos romanos em relação à distinção entre a criação intelectual e o suporte físico. Segundo o filósofo romano, o litígio tinha, em realidade, dois lados, visto que Cícero reivindicava seus livros como autor (auctor), enquanto que Dorus o fazia como comprador (emptor $)^{173}$.

Pois bem, das passagens transcritas ficou evidenciado que os romanos tinham consciência acerca da autoria de uma obra, inclusive distinguindo o suporte físico (corpus mechanicum) da criação intelectual propriamente dita (corpus mysticum) ${ }^{174}$.

${ }^{171}$ CHINELLATO, Silmara Juny de Abreu. Direito de autor e direitos da personalidade: reflexões à luz do Código Civil. Tese para Concurso de Professor Titular de Direito Civil da Faculdade de Direito da Universidade de São Paulo. São Paulo: Universidade de São Paulo, 2008. p. 45.

172 "Eu escrevi estes versos, outro ficou com as honrarias: Assim vós, aves, não fazeis os ninhos para vós, assim vós, ovelhas, não produzis a lã para vós, assim vós, abelhas, não fabricais o mel para vós, assim vós bois, puxais o arado, mas não para vós". Tradução de Ignácio Maria Poveda Velasco (VELASCO, Ignácio Maria Poveda. "Actio iniuriarum" e direito de autor. Revista de Direito Civil, Imobiliário, Agrário e Empresarial, São Paulo, ano 17, p. 109-114, jan./mar. 1993, p. 113).

173 FRAGOSO, João Henrique da Rocha. Direito autoral: Da Antiguidade à Internet. São Paulo: Quartier Latin, 2009. p. 199.

${ }^{174}$ CHINELLATO, Silmara Juny de Abreu, Direito de autor e direitos da personalidade, p. 32. Não é outra a lição de Gautier, o qual destaca que os romanos conheciam perfeitamente a noção de obra do espírito, de maneira que foram os pioneiros no que toca à distinção entre o suporte material e a obra do espírito (GAUTIER, Pierre-Yves, Propriété littéraire et artistique, p. 13). 
Todavia, ao lado da consciência dos romanos, resta-nos indagar se seria possível a utilização dos instrumentos jurídicos da época para a proteção da obra e do autor.

\section{A POSSIBILIDADE DE TUTELA DOS DIREITOS DA PERSONALIDADE DO AUTOR}

A actio iniuriarum era uma demanda relacionada com a iniuria e delitos semelhantes. Inicialmente, no período da República, o tipo da iniuria era interpretado restritamente, pois era necessário para sua configuração uma severa agressão contra uma pessoa. Porém, com o passar do tempo, a actio iniuriarum foi envolvendo um número cada vez maior de condutas, como, por exemplo, a contrariedade aos costumes e o ataque à boa fama de uma mulher ${ }^{175}$.

A extensão dada pelo pretor ao conceito de iniuria acabou, no decorrer da evolução do Direito Romano, assegurando a proteção contra qualquer lesão a um aspecto da personalidade, diferentemente do antigo conceito, que abarcava apenas as lesões físicas ${ }^{176}$.

Assim sendo, especula-se sobre a possibilidade de utilização da actio iniuriarum em casos como de plágio, de publicação sem o consentimento do autor e de desrespeito à integridade da obra ${ }^{177}$. Nessa linha, poder-se-ia afirmar, por exemplo, que a publicação de uma obra sem autorização, por desrespeitar a vontade do autor e, por conseguinte, sua própria pessoa, ensejaria a aplicação da actio iniuriarium para garantir a proteção da honra ${ }^{178}$.

\footnotetext{
175 SCHICKERT, Katharina. Der schutz literarischer urheberschaft im rom der klassischen antike. Tübingen: Mohr Siebeck, 2005. p. 63.

176 VELASCO, Ignácio Maria Poveda. "Actio iniuriarum" e direito de autor. Revista de Direito Civil, Imobiliário, Agrário e Empresarial, São Paulo, ano 17, p. 109-114, jan./mar. 1993. p. 111.

177 SCHICKERT, Katharina. Der schutz literarischer urheberschaft im rom der klassischen antike. Tübingen: Mohr Siebeck, 2005.

${ }^{178}$ Idem. p. 64. Na mesma linha, Santos Cifuentes aduz que os romanos "não concebiam que os frutos da inteligência ou da inspiração artística pudessem ser matéria de um ius especial; que o pensamento representaria um bem suscetível de proteção, à parte da matéria que serve de suporte". Entretanto, lembra que se recorria à actio iniuriarum "quando a violação importava um ataque à personalidade, em particular se não se havia cedido a
} 
Esse raciocínio foi complementado por Carlo Fadda, ao esclarecer que "assim como ofendia a personalidade a ilícita revelação das disposições testamentárias, de segredos familiares ou do conteúdo de uma carta missiva, da mesma forma ofendia a divulgação de uma obra não destinada pelo autor a vir a público" ${ }^{179}$.

A tese poderia ser aplicada em um caso ocorrido em Roma, em que um editor, sem o consentimento do autor, publicou sua obra. Trata-se do quinto livro da obra De finibus, que chegou às mãos de Balbus por meio de Atticus, o que foi severamente criticado por seu autor Cícero, pois isso ocorreu antes mesmo que Brutus, a quem foi dedicada, pudesse ter tido contato com o trabalho. Entrementes, Cícero não chegou a tomar medidas jurídicas contra Atticus, uma vez que possuíam amizade muito próxima $^{180}$.

Aliás, não somente a publicação sem autorização, mas também a própria figura do plágio poderia ser considerada ilícita e tutelada pela actio iniuriarum $^{181}$. Nesse sentido, adverte Velasco que se considerarmos a obra como projeção da personalidade de seu autor, então o plágio levaria à ofensa da personalidade e poderia ser punido com o uso da actio iniuriarum $^{182}$.

Contudo, ao lado da possibilidade de proteção da autoria, da integridade e do ineditismo, em várias passagens de textos de Marcial fica evidente a possibilidade de transferência da autoria de escritos ainda não publicados, o que certamente configuraria uma afronta ao Direito de $\mathrm{Au}$ tor atualmente em vigor.

Realmente, conforme alguns doutrinadores, a figura do ghost writer, como a conhecemos na atualidade, não era repudiada pelo Direito Romano, posto que às vezes era permitido que autores, mediante paga-

obra a ninguém" (CIFUENTES, Santos. Derechos personalíssimos. 3. ed. Buenos Aires: Astrea, 2008, p. 193-194).

179 VELASCO, Ignácio Maria Poveda. “Actio iniuriarum” e direito de autor. Revista de Direito Civil, Imobiliário, Agrário e Empresarial, São Paulo, ano 17, p. 109-114, jan./mar. 1993. p. 112.

180 SCHICKERT, Katharina. Der schutz literarischer urheberschaft im rom der klassischen antike. Tübingen: Mohr Siebeck, 2005. p. 57.

${ }^{181}$ GAUDENZI, Andrea Sirotti, Il nuovo diritto d'autore, p. 42.

182 VELASCO, Ignácio Maria Poveda. "Actio iniuriarum” e direito de autor. Revista de Direito Civil, Imobiliário, Agrário e Empresarial, São Paulo, ano 17, p. 109-114, jan./mar. 1993. p. 113. 
mento, entregassem seus trabalhos não publicados a terceiros, que os assumiriam como seus ${ }^{183}$.

De qualquer forma, o tema é bastante discutível, não sendo possível saber se a autoria poderia ser ocultada por meio de contrato e se a suspensão de tal obrigação poderia ser conseguida à força, mesmo porque a reconstrução da exata organização romana existente à época é impossível $^{184}$.

\section{O INTERESSE ECONÔMICO NA PRODUÇÃO AUTORAL}

Os romanos tinham plena ciência da existência de interesse econômico na produção autoral. É notório, por exemplo, o benefício pecuniário que desfrutavam os poetas Horácio e Virgílio junto a Caius Maecenas, estadista romano cujo nome simboliza atualmente o patronato das $\operatorname{artes}^{185}$.

A existência do interesse econômico também fica patente em uma carta de Cícero dirigida ao seu amigo e editor Atticus, onde Cícero elogia o excelente trabalho do editor na "venda" do seu discurso Pro Ligario, afirmando o autor que no futuro entregaria a Atticus, para publicação, o que viesse a escrever ${ }^{186}$.

É certo ainda que o interesse despertado pelos espetáculos teatrais abriu novas perspectivas para os autores. De fato, vale lembar que Terêncio, então escravo cartaginês, recebeu por seus versos seis mil ses-

\footnotetext{
183 Marcial, por exemplo, menciona um certo Paulo, que comprou poesias e as recitou como suas. E o próprio Marcial exigiu várias vezes de Fidentino a compra da autoria de textos, os quais poderiam, posteriormente, ser recitados em conformidade com o direito, visto que até então Marcial denominava-se dominus de suas poesias (SCHICKERT, Katharina. Der schutz literarischer urheberschaft im rom der klassischen antike. Tübingen: Mohr Siebeck, 2005. p. 71).

${ }^{184}$ Idem. p. 72.

${ }^{185}$ COSTA NETTO, José Carlos. Direito autoral no Brasil. 2. ed. São Paulo: FTD, 2008. p. 51.

${ }^{186}$ FRAGOSO, João Henrique da Rocha. Direito autoral: Da Antiguidade à Internet. São Paulo: Quartier Latin, 2009. p. 61.
} 
tércios, pagos pelo edil Cecílio ${ }^{187}$. Há, igualmente, outro relato da compra de versos do mesmo Terêncio. Segundo revelou Seutônio, os edis pagaram oito mil sestércios por duas representações da comédia "O Eunu$\operatorname{co}^{\prime \prime} 188$.

Poderíamos, ademais, para reafirmar o interesse econômico na produção intelectual, citar o caso de Plauto, "que adquiriu no teatro uma verdadeira fortuna, perdida depois no comércio, porque era simultaneamente autor, ator e diretor de companhia" ${ }^{189}$.

Porém, afora algumas exceções, deve-se notar que havia em Roma um comércio para as criações literárias e artísticas ao qual os autores estavam sujeitos de maneira muito similar àquela verificada mais tarde com a invenção da imprensa, ou seja, em Roma também era evidente a hipossuficiência dos autores.

Os autores não tinham, como os livreiros, relações comerciais para vender e espalhar as obras por Roma e suas províncias. Também não tinham condições de reproduzir as obras, o que demandava trabalho enfadonho e, às vezes, necessitava de um copista com tal instrução que não era fácil encontrar. Isso sem falar na adulação e no servilismo, especialmente diante dos imperadores, o que acabava por ofuscar, muitas vezes, o gênio de muitos artistas romanos, que não podiam criar com independên$\operatorname{cia}^{190}$.

Realmente, até mesmo autores de sucesso não chegaram a se beneficiar com os lucros das vendas de seus textos, valendo aqui, mais uma vez, citar Marcial, que apesar de toda a popularidade, viveu e morreu pobre, escrevendo: "Que me importa saber que os nossos soldados leem meus versos no interior da Dácia, e que os meus epigramas são cantados no fundo da Bretanha, se isto não aproveita à minha bolsa?" ${ }^{191}$.

Tácito também explicita a situação dos escritores no "Diálogo dos oradores" (Dialogus de oratoribus), evidenciando que o interesse

187 JORDÃO, Levy Maria. A propriedade litteraria não existia entre os romanos. In: Historia e Memrias da Academia Real das Sciencias de Lisboa: Classe de Sciencias Moraes, Políticas, e Bellas-lettras, tomo II, parte II. Lisboa: Academia, 1863. p. 10.

${ }^{188}$ ROCHA, Daniel. Direito de autor. São Paulo: Irmãos Vitale, 2001. p. 15.

189 JORDÃO, Levy Maria. A propriedade litteraria não existia entre os romanos. In: Historia e Memorias da Academia Real das Sciencias de Lisboa: Classe de Sciencias Moraes, Políticas, e Bellas-lettras, tomo II, parte II. Lisboa: Academia, 1863. p. 12.

${ }^{190}$ Idem. p. 4-7.

${ }^{191}$ Idem. p. 3. 
moral era quase o único incitamento que impelia boa parte dos autores: "Os versos não dão fortuna, o seu fruto limita-se a um prazer curto, a louvores frívolos e estéreis; e a fama a que os poetas se sacrificam, e que confessam ser o único preço de seus escritos, ainda é inferior à dos oradores" ${ }^{192}$.

Ademais, é curioso observar que os romanos, tal como corriqueiramente vemos na atualidade, pagavam vultosas quantias por obras de arte de artistas já falecidos. Não davam, no entanto, o mesmo valor ao trabalho dos artistas vivos, o que fica muito claro nas palavras de Sêneca: "Adoramos as imagens e desprezamos os que as esculpem" 193.

Vê-se, assim, que os autores e artistas, no geral, não obtinham grande compensação financeira pelos seus trabalhos. Eram impulsionados, em realidade, mais pelo interesse moral, pela glória e pelo reconhecimento dos concidadãos, do que propriamente pela pretensão de lucro com a exploração da obra.

Enfim, ao lado de todas essas dificuldades, deve-se ainda acrescentar que havia na sociedade romana repulsa e reprovação pela conduta do criador que explorava economicamente sua obra, o que configurava mais um obstáculo para o desenvolvimento dos direitos patrimoniais de autor ${ }^{194}$.

8. A defesa do autor como um problema atinente aos direitos

reais

O problema atinente ao reconhecimento dos chamados direitos patrimoniais do autor está ligado ao fato de se saber se o Direito Romano admitia a existência de direitos intelectuais. É certo que o livro, antes de sua publicação, era propriedade de seu autor, o qual poderia, inclusive, mantê-lo inédito. No entanto, a indagação que deve ser respondida referese à situação depois da venda ou cessão da obra.

Parece-nos acertada, apesar da grande polêmica existente sobre o tema, a posição de Lipszyc, a qual afirma que em Roma a "criação intelectual era regida pelo direito de propriedade comum”, já que o autor, ao

192 JORDÃO, Levy Maria. A propriedade litteraria não existia entre os romanos. In: Historia e Memorias da Academia Real das Sciencias de Lisboa: Classe de Sciencias Moraes, Políticas, e Bellas-lettras, tomo II, parte II. Lisboa: Academia, 1863. p. 2-3.

193 EBOLI, João Carlos de Camargo. Pequeno mosaico do direito autoral. São Paulo: Irmãos Vitale, 2006. p. 18.

${ }^{194}$ LEITE, Eduardo Lycurgo. Plágio e outros estudos em direito de autor. Rio de Janeiro: Lumen Juris, 2009. p. 116. 
criar uma obra literária ou artística, produzia uma coisa, a qual poderia ser alienada por seu proprietário, como qualquer outro bem material ${ }^{195}$.

Seja como for, a questão relativa à res incorporalis no Direito Romano está longe de ser pacífica. Pode-se citar, nessa linha, o estudo de Marie Claude D'Ock, o qual "atesta com robustez, que havia estruturas sociais e econômicas a demonstrar que a noção de 'propriedade literária' em Roma estava presente, ainda que indiretamente e em regiões localizadas" ${ }^{196}$.

A controvérsia surge, precipuamente, em razão do tratamento dado pelo Direito Romano aos textos literários (scriptura) e às pinturas (pictura).

De acordo com Gaio, se alguém escreve em papiro ou pergaminho, ainda que com letras de ouro, o objeto pertence ao proprietário do papiro ou pergaminho. O mesmo não acontecia na hipótese de pintura, que pertencia ao pintor, a despeito de ter sido feita em tela alheia ${ }^{197}$. O jurisconsulto considerava de difícil explicação a diversidade do tratamento dado ao tema (cuius diversitate vix idonea ratio redditur), mas deixou claro que a tela é que acede à pintura ${ }^{198}$.

A ideia também foi acolhida por Justiniano, nas Institutas (553 a.C.), o que pode ser observado no Livro Segundo, que trata "Da divisão das coisas" (Inst. 2.1.33 e Inst. 2.1.34) ${ }^{199}$. De fato, a solução acolhida pelo direito justinianeu é aquela que considerava principal não a coisa de maior valor ou volume, mas sim aquela que imprimia ao todo sua função social. Assim, no caso particular da pictura, os sabinianos consideravam principal a tela, enquanto que os proculianos a obra pintada. Justiniano,

\footnotetext{
195 LIPSZYC, Delia.. Derecho de autor y derechos conexos. Buenos Aires: UNESCO, 1993. p. 29.

${ }^{196}$ CHINELLATO, Silmara Juny de Abreu. Direito de autor e direitos da personalidade: reflexões à luz do Código Civil. Tese para Concurso de Professor Titular de Direito Civil da Faculdade de Direito da Universidade de São Paulo. São Paulo: Universidade de São Paulo, 2008. p. 43.

${ }^{197}$ ROCHA, Daniel. Direito de autor. São Paulo: Irmãos Vitale, 2001. p. 16.

198 CHINELLATO, Silmara Juny de Abreu. Direito de autor e direitos da personalidade: reflexões à luz do Código Civil. Tese para Concurso de Professor Titular de Direito Civil da Faculdade de Direito da Universidade de São Paulo. São Paulo: Universidade de São Paulo, 2008. p. 29.

199 Ibidem.
} 
interrompendo a disputa, considerou que o quadro pertencia ao pintor, que deveria, porém, indenizar o valor da tela ${ }^{200}$.

Em relação ao tema, ensina Moreira Alves que nas hipóteses de acessão de coisa móvel a coisa móvel, "quanto à scriptura, sempre se julgou, no direito romano, que o escrito acede ao material sobre o qual se escreve; assim, se alguém escrevesse em material alheio, o escrito passava, materialmente (e não literalmente)" ao dono da matéria ${ }^{201}$.

Já no caso de pintura sobre tela alheia, destaca o romanista que no direito clássico havia divergência no que toca à solução do problema. Alguns entendiam que "as tintas acediam à tela, e, assim, o proprietário dela se tornava proprietário do quadro; outros eram de opinião contrária o quadro passava à propriedade do pintor". No entanto, ao final, como já mencionamos, prevaleceu a tese de que o quadro passava à propriedade do pintor, opinião seguida por Justiniano ${ }^{202}$.

Diante das soluções encontradas pelo Direito Romano, bem como com respaldo nas lições de Moreira Alves, conclui Chinellato que "os romanos tinham plena consciência da diferença entre suporte físico da obra e a criação intelectual que deu origem à terminologia de fundamental importância para o direito autoral: corpus mechanicum e corpus mysticum" 203 .

Em sentido contrário, Brunner assevera que "o direito romano não conhecia nenhuma diferenciação entre a propriedade do objeto no qual um trabalho intelectual estava incorporado e o trabalho em si mesmo" ${ }^{204}$. Não é outro o entendimento de Picard, o qual lembra que repugnava ao espírito eminentemente positivo e materialista dos romanos a

200 SANFILIPPO, Cesare. Istituzioni di diritto romano. 10. ed. Soveria Mannelli: Rubbettino, 2002. p. 205.

${ }^{201}$ ALVES, José Carlos Moreira. Direito Romano. 7. ed. Rio de Janeiro: Forense, 1997, v. 1. p. 299.

202 Ibidem.

${ }^{203}$ CHINELLATO, Silmara Juny de Abreu. Direito de autor e direitos da personalidade: reflexões à luz do Código Civil. Tese para Concurso de Professor Titular de Direito Civil da Faculdade de Direito da Universidade de São Paulo. São Paulo: Universidade de São Paulo, 2008. p. 32.

204 Tradução livre: "Das römische Recht kannte keine Differenzierung zwischen dem Eigentum an dem Gegenstand, in dem ein geistiges Werk verkörpert war und dem Werk selbst" (BRUNNER, Richard, Urheber-und leistungsschutzrechtliche Probleme der Musikdistribution im Internet: unter besonderer Berücksichtigung der Richtlinie 2001/29/EG und ihrer Umsetzung in deutsches Recht, p. 13). 
ideia de que uma "uma coisa puramente intelectual pudesse ser objeto de um direito" 205.

Levy Maria Jordão, com efeito, atento ao problema mencionado, adverte que "a diversidade da solução das duas hipóteses não provinha da diferença entre o papel e a escrita, entre o quadro e a tela", mas sim decorria do princípio da praevalentia ${ }^{206}$.

Parece-nos, a despeito das inúmeras interpretações voltadas para a análise da questão da pictura e da scriptura, que os romanos não estavam preocupados com nenhum tipo de questionamento envolvendo uma suposta "propriedade intelectual", mas sim tinham em vista apenas a resolução do problema da atribuição da propriedade material em caso de escrito ou de pintura feitos em bens alheios ${ }^{207}$.

\section{CONSIDERAÇÕES FINAIS}

A partir dessas premissas, é fácil de se constatar que o Direito de Autor não existia em Roma e muito menos na Grécia. Em Roma, apenas de forma embrionária poderia ser assegurada a proteção de alguns aspectos da personalidade do autor, que não obstante a ausência de registro histórico, poderiam ser tutelados pela actio iniuriarum.

Ainda, ao que tudo indica, os romanos tinham consciência da distinção entre o corpus mechanicum e o corpus mysticum, porém, isso não outorgou à res incorporalis uma proteção patrimonial. E não poderia ser diferente, pois seria bastante difícil pretender que um povo aristocrático, pragmático e guerreiro, preocupado com questões concretas, pudesse ter reconhecido ao autor o direito exclusivo de reprodução de sua obra, bem como a remuneração pela produção de cada novo exemplar dela.

Assim sendo, a despeito do comércio de obras intelectuais ter se desenvolvido muito em Roma, os autores não obtinham grande compensação financeira pelos seus trabalhos, pois acabavam sendo explorados

\footnotetext{
205 PICARD, Edmond. Le Droit Pur. Paris: Ernest Flammarion, 1908. p. 93.

206 JORDÃO, Levy Maria, A propriedade litteraria não existia entre os romanos, p. 14.

${ }^{207}$ Nesse sentido também se manifesta Rehbinder, para quem a disputa entre os sabinianos e proculianos em torno da pintura ou escrita feita em objeto alheio diz respeito meramente ao problema da aquisição da propriedade de um novo bem, que surge como decorrência de uma especificação, não tendo a discussão nenhuma relação com o direito aos bens intelectuais (REHBINDER, Manfred, Urheberrecht, p. 7).
} 
pelos editores e comerciantes. Por isso, pode-se afirmar que a glória e o reconhecimento dos concidadãos impulsionavam a produção de obras do espírito, ficando o lucro com sua exploração relegado a um segundo plano.

Por conseguinte, acreditamos que, não obstante a importância dos desenvolvimentos ocorridos na Antiguidade Clássica, os direitos autorais não foram reconhecidos nas sociedades grega e romana, pois o que existiu foi apenas uma proteção embrionária e fragmentada de alguns pontos da matéria, que não pode ser comparada com a tutela posteriormente outorgada pelo Estatuto da Rainha Ana (1710) e pelos decretos franceses de 1791 e 1793.

\section{REFERÊNCIAS BIBLIOGRAFICAS}

ALVES, José Carlos Moreira. Direito romano. 7. ed. Rio de Janeiro: Forense, 1997, v. 1.

BRUNNER, Richard. Urheber- und leistungsschutzrechtliche Probleme der Musikdistribution im Internet: unter besonderer Berücksichtigung der Richtlinie 2001/29/EG und ihrer Umsetzung in deutsches Recht. Berlin: Tenea, 2004.

CARBONI, Guilherme. Direito autoral e autoria colaborativa: na Economia da Informação em Rede. São Paulo: Quartier Latin, 2010.

CHINELLATO, Silmara Juny de Abreu. Notas sobre plágio e autoplágio. Revista do Instituto dos Advogados de São Paulo, São Paulo, v. 29, p. 305-328, jan./jun. 2012.

. Direito de autor e direitos da personalidade: reflexões à luz do Código Civil. Tese para Concurso de Professor Titular de Direito Civil da Faculdade de Direito da Universidade de São Paulo. São Paulo: Universidade de São Paulo, 2008.

CIFUENTES, Santos. Derechos personalíssimos. 3. ed. Buenos Aires: Astrea, 2008.

COSTA NETTO, José Carlos. Direito autoral no Brasil. 2. ed. São Paulo: FTD, 2008.

EBOLI, João Carlos de Camargo. Pequeno mosaico do direito autoral. São Paulo: Irmãos Vitale, 2006. 
FRAGOSO, João Henrique da Rocha. Direito autoral: Da Antiguidade à Internet. São Paulo: Quartier Latin, 2009.

GAUDENZI, Andrea Sirotti. Il nuovo diritto d'autore. Santarcangelo di Romagna: Maggioli, 2009.

GAUTIER, Pierre-Yves. Propriété littéraire et artistique. 7. ed. Paris: PUF, 2010.

HUNGRIA, Nélson. Comentários ao Código Penal. 5 ed. Rio de Janeiro: Forense, 1982, v. 6.

JORDÃO, Levy Maria. A propriedade litteraria não existia entre os romanos. In: Historia e Memorias da Academia Real das Sciencias de Lisboa: Classe de Sciencias Moraes, Políticas, e Bellas-lettras, tomo II, parte II. Lisboa: Academia, 1863, p. 1-15.

LEITE, Eduardo Lycurgo. Plágio e Outros Estudos em Direito de Autor. Rio de Janeiro: Lumen Juris, 2009.

LIPSZYC, Delia.. Derecho de autor y derechos conexos. Buenos Aires: UNESCO, 1993.

MENDES, Mauro. Virgílio e os cantadores. Disponível em: $<$ http://www.arquivors.com/mmendes_virgilio.pdf >. Acesso em: 9 jan. 2011.

PICARD, Edmond. Le Droit Pur. Paris: Ernest Flammarion, 1908.

REHBINDER, Manfred. Urheberrecht. 16. ed. München: C. H. Beck, 2010.

ROCHA, Daniel. Direito de autor. São Paulo: Irmãos Vitale, 2001.

SANFILIPPO, Cesare. Istituzioni di diritto romano. 10. ed. Soveria Mannelli: Rubbettino, 2002.

SCHICKERT, Katharina. Der Schutz literarischer Urheberschaft im Rom der klassischen Antike. Tübingen: Mohr Siebeck, 2005.

VELASCO, Ignácio Maria Poveda. "Actio iniuriarum" e direito de autor. Revista de Direito Civil, Imobiliário, Agrário e Empresarial, São Paulo, ano 17, p. 109-114, jan./mar. 1993.

ZANINI, Leonardo Estevam de Assis. O Estatuto da Rainha Ana: estudos em comemoração dos 300 anos da primeira lei de copyright. Revista de Doutrina da $4^{\text {a }}$ Região, Porto Alegre, n. 39, dez. 2010. Disponível em: <http://www.revistadoutrina.trf4.jus.br/artigos/edicao039/leonardo _zanini.html>. Acesso em: 10 jan. 2013. 
